\title{
PROPOSTA SIMPLIFICADA DE AVALIAÇÃO DA GESTÃO DA QUALIDADE EM ENTIDADES DE CLASSE
}

\author{
Damiana Machado de Almeida ${ }^{1}$, Vânia Medianeira Flores Costa ${ }^{1}$, Clarissa Peterini Alves ${ }^{1}$, Andressa Schaurich dos \\ Santos 1 \\ Universidade Federal de Santa Maria - UFSM ${ }^{1}$ \\ adm.damiana@gmail.com, vania.costa@ufsm.br, clarissa_peterini@yahoo.com.br, \\ dessaschaurich@gmail.com
}

\section{Resumo}

Este artigo tem como objetivo propor um modelo simplificado de avaliação da gestão das entidades de classe que possibilite mensurar e classificar os diferentes níveis de gestão, no intuito de auxiliar as organizações a melhorar o seu desempenho organizacional. Foi realizada uma pesquisa bibliográfica acerca da evolução histórica da Gestão da Qualidade utilizando-se os oito critérios do Modelo de Excelência da Gestão (MEG) da Fundação Nacional da Qualidade (FNQ) - Liderança, Estratégias e Planos, Clientes, Sociedade, Informações e Conhecimento, Pessoas, Processos e Resultados. A partir da revisão bibliográfica da qualidade e da gestão por excelência apresentou-se uma Proposta Simplificada de Avaliação da Gestão da Qualidade em Entidades de Classe, que pretende auxiliar as lideranças em uma visão sistêmica necessária para gerir esse tipo de organização, tratando-se de um instrumento capaz de fornecer subsídios para a tomada de decisão e de constituir-se em uma entrada para o plano de aperfeiçoamento da gestão organizacional.

Palavras-chave: Gestão da Qualidade; Modelo de Excelência; Entidades de classe; Proposta Simplificada de Avaliação da Gestão da Qualidade.

\section{SIMPLIFIED PROPOSAL FOR ASSESSMENT OF QUALITY MANAGEMENT ON CLASS ENTITIES}

\begin{abstract}
This article aims to propose a simplified model for assessing the management of associations that enables to measure and classify the different levels of management in order to help organizations improve their organizational performance. It was performed a literature search on the historical evolution of quality management using the eight criteria of the Excellence Model Management (MEG) of the National Quality Foundation (FNQ) - Leadership, Strategies and Plans, Customers, Society, Information and Knowledge, People, Processes and Outcomes. From the description of the quality and management for excellence presented a Proposed Simplified Evaluation of Quality Management in Class Entities, which aims to assist leaders in a systemic vision necessary to manage this type of organization, as this is a instrument capable of supplying subsidies for decision making and provide input into a plan for the improvement of organizational management.
\end{abstract}

Keywords: Quality Management; Excellence Model; Entities class; Proposed simplified evaluation of quality management.

\section{Introdução}

Frente às mudanças ocorridas no mercado, as pequenas e médias empresas precisam de diferenciais competitivos. Para Almeida e Asai (2001), estas se destacam neste ambiente quando buscam a união por meio de parcerias, redes, associações ou entidades que favorecem o desenvolvimento de seus negócios. Entretanto, torna-se relevante para a organização obter 
qualidade nos seus produtos e serviços com vistas a excelência e aos interesses de seus stakeholders.

No intuito de discorrer-se sobre a qualidade, a presente pesquisa delimita-se ao universo das Entidades de Classe e justifica-se pela necessidade dos dirigentes em mensurar o nível de desempenho das suas gestões, ou seja, também empenham-se em atingir e manter a qualidade ao ponto de participarem constantemente em premiações deste meio. Como modelo base para este constructo, utilizou-se o Modelo de Excelência da Gestão (MEG) criado pela Fundação Nacional da Qualidade (FNQ) por compreender que este abrange o conhecimento necessário à busca pela Excelência na Gestão, permitindo ao gestor a visão sistêmica necessária para o progresso de seu negócio.

Nesse sentido, a presente pesquisa propõe-se em desenvolver um modelo simplificado de avaliação da gestão das entidades de classe que possibilite mensurar e classificar os diferentes níveis de gestão, no intuito de auxiliar essas a melhorar o seu desempenho organizacional. Inicialmente, são discutidos os conceitos de gestão da qualidade e critérios de excelência, baseando-se em publicações no âmbito acadêmico e empresarial. Em seguida, apresenta-se o modelo de gestão da excelência referência para este estudo e discorre-se sobre os oito critérios nele abordados. Logo, disserta-se sobre o método utilizado para elaborar este estudo. Em seguida, apresentam-se a Proposta de Avaliação da Gestão das Entidades de Classe fundamentando-os com o MEG, e por fim as contribuições deste artigo a respeito do assunto abordado.

\section{A gestão da qualidade}

Segundo Garvin (2002), a qualidade evoluiu do departamento de controle para o sistema de gestão, abrangendo toda a organização. Essa evolução divide-se em quatro fases: a Inspeção, o Controle Estatístico da Qualidade, a Garantia da Qualidade e a Gestão da Qualidade. Cada fase possui sua orientação e enfoque, sua ênfase, seus métodos, o papel dos profissionais e seus responsáveis pela qualidade, conforme Quadro 1.

\begin{tabular}{|c|c|c|c|c|c|}
\hline Fases & $\begin{array}{c}\text { Orientação } \\
\text { e enfoque }\end{array}$ & Ênfase & Métodos & $\begin{array}{c}\text { Papel dos } \\
\text { profissionais }\end{array}$ & $\begin{array}{c}\text { Responsável } \\
\text { pela qualidade }\end{array}$ \\
\hline Inspeção & $\begin{array}{c}\text { Inspecionar } \\
\text { a qualidade. }\end{array}$ & $\begin{array}{c}\text { Uniformidade } \\
\text { do produto. }\end{array}$ & $\begin{array}{c}\text { Instrumentação } \\
\text { de medição. } \\
\text { classificação, } \\
\text { contagem e } \\
\text { avaliação. }\end{array}$ & $\begin{array}{c}\text { Departamento de } \\
\text { inspeção. }\end{array}$ \\
\hline $\begin{array}{c}\text { Controle } \\
\text { Estatístico } \\
\text { da } \\
\text { qualidade }\end{array}$ & $\begin{array}{c}\text { Controlar a } \\
\text { qualidade. }\end{array}$ & $\begin{array}{c}\text { Uniformidade de } \\
\text { produtos com } \\
\text { menos inspeção. }\end{array}$ & $\begin{array}{c}\text { Ferramentas e } \\
\text { Técnicas } \\
\text { estatísticas. }\end{array}$ & $\begin{array}{c}\text { Solução de } \\
\text { problemas e } \\
\text { aplicação de } \\
\text { métodos estatísticos. }\end{array}$ & $\begin{array}{c}\text { Departamentos } \\
\text { de produção e } \\
\text { engenharia. }\end{array}$ \\
\hline $\begin{array}{c}\text { Garantia } \\
\text { da }\end{array}$ & $\begin{array}{c}\text { Construir a } \\
\text { qualidade. }\end{array}$ & $\begin{array}{c}\text { Toda cadeia de } \\
\text { fabricação e a } \\
\text { contribuição de } \\
\text { grupos } \\
\text { funcionais para } \\
\text { impedir falhas } \\
\text { de qualidade. }\end{array}$ & Programas e & $\begin{array}{c}\text { Sistemas. } \\
\text { Planejamento, } \\
\text { medição da } \\
\text { qualidade e projeto } \\
\text { de programas. }\end{array}$ & $\begin{array}{c}\text { Todos os } \\
\text { departamentos e } \\
\text { a alta } \\
\text { administração se } \\
\text { envolvendo }\end{array}$ \\
$\begin{array}{c}\text { Gestão da } \\
\text { Qualidade }\end{array}$ & $\begin{array}{c}\text { Gerenciar a } \\
\text { Qualidade. }\end{array}$ & $\begin{array}{c}\text { As necessidades } \\
\text { do mercado e do } \\
\text { cliente. }\end{array}$ & $\begin{array}{c}\text { Planejamento } \\
\text { estratégico, } \\
\text { estabelecimento } \\
\text { de objetivos. }\end{array}$ & $\begin{array}{c}\text { Estabelecimento de } \\
\text { metas, treinamento, } \\
\text { consultoria a outros } \\
\text { departamentos e } \\
\text { desenvolvimento de } \\
\text { programas. }\end{array}$ & $\begin{array}{c}\text { Todos na } \\
\text { empresa, e a alta } \\
\text { administração } \\
\text { exercendo forte } \\
\text { liderança. }\end{array}$ \\
\hline
\end{tabular}


Com estas etapas da qualidade, observou-se que "as organizações tornam-se núcleos de competências específicas, concentrando-se cada vez mais em fazer aquilo em que são realmente excelentes e delegando a terceiros a execução das demais funções e atividades" (FNQ, 2006, p. 5). Nota-se, que a qualidade voltada apenas para produtos entregues aos clientes, já é uma etapa obsoleta no cenário mundial (FNQ, 2009). Para Carvalho e Paladini (2012) a evolução no conceito da qualidade deu-se com a necessidade de aliarem-se as organizações que buscam excelência os diversos interesses de seus stakeholders.

\section{Critérios de Excelência da Gestão}

A mudança de todos os paradigmas ocorridos durante a evolução da qualidade intensifica-se com a busca pela excelência na gestão, esta uma tarefa incessante de todas as organizações que almejam oferecer qualidade naquilo que fazem. Peter (2008 apud LIMA, 2013) acredita que um dos caminhos para a excelência é a busca pela pró-atividade, essa amparada pelo incentivo de aprimoramento, na qual o aprendizado dá-se pelo ensaio e erro. Também para esse autor, tornase enriquecedor para organizações que ambicionam a excelência apreender com clientes, estimular a independência, ou seja, autonomia dos colaboradores; enxergar seus cooperadores como peças-chave para o sucesso; ter foco, ou seja, se ater às suas competências e aos seus conhecimentos; ter simplicidade e mobilidade, por meio da adequação das necessidades do mercado e dos clientes.

Para Marques (2006) implantar a gestão de excelência é um desafio para qualquer organização. É nesse contexto que o Modelo de Excelência da Gestão (MEG) é utilizado pela FNQ para avaliar, diagnosticar e desenvolver o sistema de gestão de organizações. O modelo é alicerçado por um conjunto de conceitos que o fundamentam e estruturado por critérios, itens e marcadores que expressam a compreensão sobre a Excelência em Gestão (FNQ, 2009), conforme Figura 1.

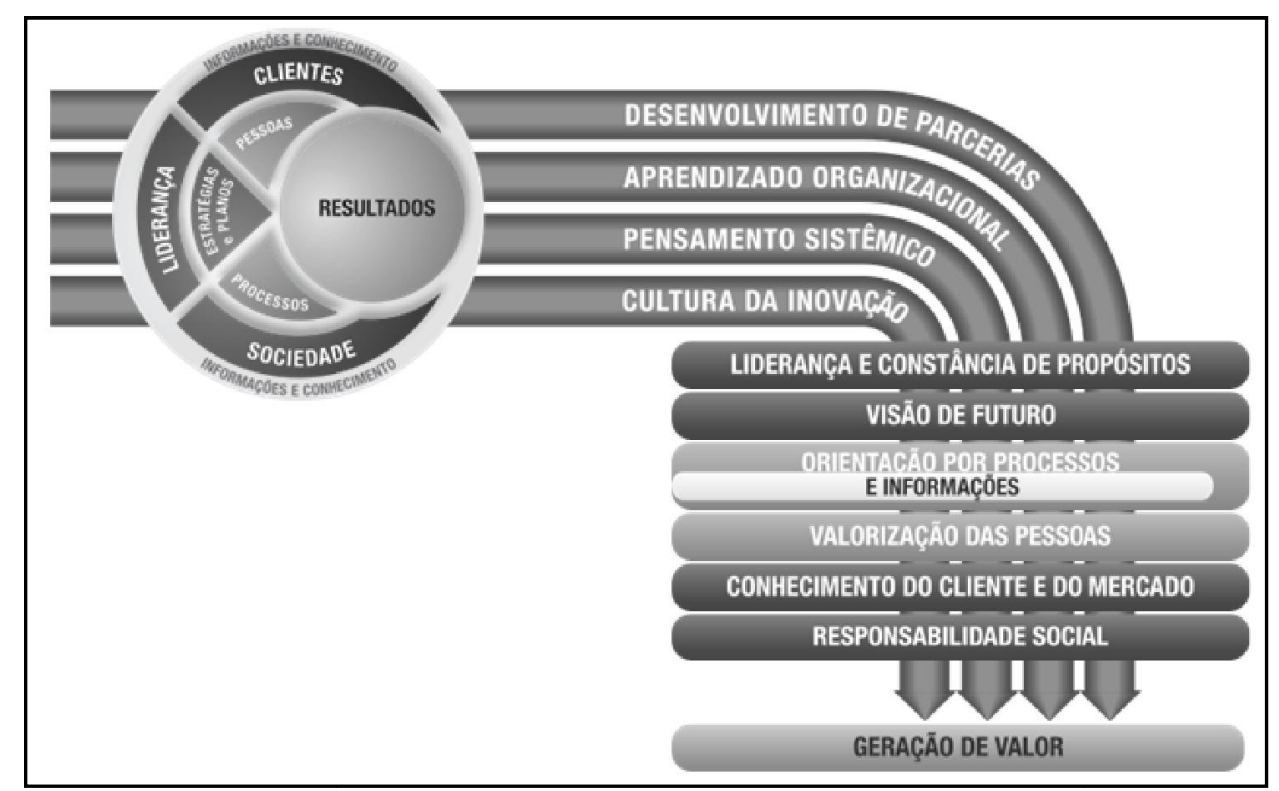

Figura 1 - Modelo de Excelência da Gestão: Correlação de fundamentos e critérios Fonte: FNQ (2013)

Os fundamentos desse modelo expressam a base teórica reconhecida internacionalmente e traduzem-se em processos gerenciais ou fatores de desempenho que são encontrados em organizações de Classe Mundial que buscam aperfeiçoar-se e adaptar-se às transformações globais (FNQ, 2009). São 11 fundamentos, entre eles: 1) Pensamento sistêmico; 2) Aprendizado organizacional; 3) Cultura de inovação; 4) Liderança e constância de propósitos; 5) Orientação 
por processos e informações; 6) Visão de futuro; 7) Geração de valor; 8) Valorização de pessoas; 9) Conhecimento sobre o cliente e o mercado; 10) Desenvolvimento de parcerias; e 11) Responsabilidade social. E os oitos critérios que permitem colocar em prática os fundamentos do MEG são: 1) Liderança; 2) Estratégias e planos; 3) Clientes; 4) Sociedade; 5) Informações e conhecimento; 6) Pessoas; 7) Processos; e 8) Resultados. Os primeiros sete critérios compreendem os processos gerenciais, o último critério relaciona-se aos resultados obtidos pela organização.

A relação entre fundamentos e critérios pode ser observada na Figura 1 representativa do MEG, na qual simboliza a empresa, organizados de forma sistêmica, evidenciam seu caráter interdependente e complementar que visam à geração de resultados.

Pode-se dizer com base na Figura 1 que os critérios de excelência estão correlacionados com os fundamentos da excelência. Estes fundamentos implícitos dão sustentação às práticas a eles relacionadas. De acordo com o objetivo deste estudo em propor um modelo de avaliação da excelência em gestão nas entidades de classe, faz-se necessário aprofundar-se sobre os 8 critérios que definem esse grau.

\subsection{Liderança}

Cabe à liderança disseminar os valores e os princípios organizacionais com a finalidade de desenvolver o espírito de comprometimento da equipe, em busca dos mesmos ideais. Isso se dá por meio da comunicação que deve ocorrer entre todos os envolvidos, incluindo partes externas à organização, como fornecedores e revendedores, para que esse comprometimento aconteça (BORGES e BAYLÃO, 2013). De acordo com Hunter (2006), a função do líder é agregar valor para a organização e dar o suporte necessário à equipe. Além de planejar, organizar, coordenar e controlar os negócios, ele também é responsável pelo clima e pela cultura da organização. Deve focar a equipe na direção do desempenho, tirando-a da situação de conforto e fazendo-a com que se busque progresso.

Compreende-se no MEG, em relação à questão da liderança com a preocupação em analisar detalhadamente as práticas de três itens que totalizam 18 questões abertas. Neste estudo os itens avaliados são: 1) Liderança Corporativa; 2) Exercício da Liderança e promoção da cultura da excelência; 3) Análise do desempenho da organização.

\subsection{Estratégias e Planos}

Na acepção da administração, Fernandes e Berton (2006, p. 5) creem que estratégia estende-se ao "sentido de concretizar uma situação futura desejada, tendo em conta as oportunidades que o mercado oferece, por um lado, e os recursos de que a organização dispõe, por outro". Para FNQ (2009), a implantação das estratégias é avaliada por intermédio de indicadores que monitoram o desenvolvimento das ações estratégicas por meio dos resultados quantitativos.

A contribuição da equipe para a execução das estratégias torna-se essencial para alcançaremse os planos de ação, as metas e os objetivos. Cabe aos líderes disseminar e comprometer seus comandados nas diretrizes da organização, motivando-os a construir o caminho para alcançar tais objetivos (FNQ, 2009). O MEG analisa as estratégias e planos sob o viés da formulação das estratégias, ou seja, aborda processos que contribuem para geração da estratégia. Também, analisa-se esse critério sob o viés da implementação das estratégias, este que pretende assegurar a realização e atualização de estratégias. Nesses itens totalizam-se 10 questões abertas.

\subsection{Clientes}

Para Malaquias (2012), a razão de existir das organizações são os clientes, por isso é vital que conheçam e entendam suas necessidades, buscando surpreendê-los positivamente. A maneira 
para conhecer tais necessidades é pesquisando e compreendendo as suas demandas e expectativas, bem como os segmentos do mercado de acordo com os nichos de atuação. Dessa forma, é possível utilizar-se de instrumentos no âmbito do marketing, visando o monitoramento (FNQ, 2009).

Logo, torna-se imprescindível o foco no cliente, na qual se geram ações que aproxime a empresa aos seus consumidores, visando sua fidelização. Por isso, no MEG, mais especificamente no critério 3 , abordam-se os processos gerenciais relativos ao tratamento de informações de consumidores, de mercado e à comunicação com o setor, clientes atuais e potenciais. Nesse critério divide-se em dois itens a serem analisados a imagem e conhecimento do mercado e o relacionamento com os clientes, que se totalizam em 12 questões abertas.

\subsection{Sociedade}

Recomenda-se para organizações que se preocupem em proporcionar o desenvolvimento nacional, regional, local e setorial da sociedade, executando e apoiando projetos sociais e buscando a qualidade de vida da população (PADULA, 2012). Arrebola (2013) complementa que as organizações socialmente responsáveis, além de atenderem aos seus deveres legais, preocupam-se em atender aos quesitos de responsabilidade social. Essa conscientização, e consequentemente as atitudes, devem ser coletivas, envolvendo colaboradores, diretores, gerentes, fornecedores, acionistas, parceiros, enfim, todos os envolvidos com o negócio da organização.

Além de representar uma estratégia na busca de um retorno econômico-social, institucional, a responsabilidade social é um dever da organização para com a sociedade e com o ecossistema, devendo prevenir, identificar e tratar quaisquer impactos negativos, diretos ou indiretos, em consequência de seus produtos, processos e instalações (FNQ, 2009). É nesse contexto que o critério da sociedade no MEG analisa o tratamento das demandas da sociedade e do meio ambiente, e ao desenvolvimento social, por meio de 11 questões abertas direcionadas aos gestores das organizações.

\subsection{Informações e Conhecimento}

Segundo a FNQ (2009) faz-se necessário o sistema de informação a fim de desenvolver e disponibilizar ferramentas e tecnologias eficazes para atender as necessidades identificadas pelos usuários. Outro benefício identificado pelas organizações é a transformação da informação em conhecimento. Segundo Santiago Jr (2004) pessoas aliadas e integradas a tecnologias e com maiores ambições, transformam informações em conhecimento e por consequência em ações empresariais de sucesso. Assim, de acordo com as normas da FNQ (2009), a obtenção de informações e a sua manutenção propiciam a organização conhecer seu grau de competitividade e de excelência a partir da comparação externa de seus resultados financeiros e não financeiros, isso dar-se com aplicação de 9 questões que abrangem esse tema.

\subsection{Pessoas}

O talento humano passou a ser tão importante quanto o próprio negócio, pois é o elemento essencial para sua preservação, consolidação e o sucesso organizacional (BORGES e BAYLÃO, 2013). Torna-se complemento disso, o papel da Gestão de Pessoas em "obter o comprometimento das pessoas na realização das atividades do projeto, visando atingir seus objetivos e propiciar a essas pessoas condições para atingir seus objetivos pessoais e individuais" (TRAVASSOS, 2008 p. 65). Neste critério abordado pela FNQ (2009), o intuito é analisar os gerenciais relativos à configuração de equipes de alto desempenho, ao desenvolvimento de competências das pessoas e à manutenção do seu bem-estar, para isso o MEG conta com 14 
questões abertas que compreendem os temas: Sistemas de trabalho; Capacitação e desenvolvimento; e Qualidade de Vida.

\subsection{Processos}

Macedo (2012) comenta que os processos têm o objetivo de adotar critérios que atendam a necessidade e a expectativa dos clientes em relação ao produto ou serviço que está sendo desenvolvido. Para Oliveira $(2006$, p. 8) " [...] processo é um conjunto estruturado de atividades sequenciais que apresentam relações lógicas entre si, com a finalidade de atender e, preferencialmente, suplantar as necessidades e as expectativas dos clientes externos e internos da empresa".

Nesse critério o MEG analisou-se 3 itens que totalizam 18 questões abertas, são eles: Processos principais do negócio e processos de apoio; Processos relativos a fornecedores; e Processos Econômicos financeiros. O controle de processos justifica-se pela necessidade de monitoramento no atendimento das necessidades e expectativas do cliente e de outras partes interessadas. Os responsáveis pelos processos na organização atuam corretiva e preventivamente para reverter às desconformidades encontradas em cada processo. Além disso, visa-se identificar possíveis melhorias, para que se agregue valor aos clientes e aos stakeholders.

\subsection{Resultados}

Quanto aos resultados estes devem ser analisados de forma constante e comparativa em relação ao ciclo anterior. Considerando-se o econômico-financeiro como variável, o relativo aos clientes, ao mercado, à sociedade, às pessoas, aos processos principais do negócio e de apoio, e também relacionada à fornecedores (FNQ, 2009).

Giovanoni (2013) ressalta que essas análises servem para nortear o empreendimento com desempenho positivo e obter os resultados estratégicos almejados pelo público interessado. Martins e Costa Neto (1998) corroboram com o exposto, destacando que os resultados são monitorados por meio da análise periódica dos indicadores criados para várias perspectivas. Dessa forma, neste critério totalizam-se 6 questões abertas para analisar todos os resultados obtidos pela organização. Finaliza-se assim, o MEG proposto pela FNQ (2009), na qual se observa de forma resumida no Quadro 2.

\begin{tabular}{|c|c|c|}
\hline Critérios & Itens & $\begin{array}{l}\text { Número de } \\
\text { questões por } \\
\text { critério }\end{array}$ \\
\hline \multirow{3}{*}{ 1. Liderança } & 1.1 Governança Corporativa & \multirow{3}{*}{18 questões } \\
\hline & 1.2 Exercícios da Liderança e Promoção da Cultura da Excelência & \\
\hline & 1.3 Análise do Desempenho da Organização & \\
\hline \multirow{2}{*}{ 2. Estratégias e Planos } & 2.1 Formulação das Estratégias & \multirow{2}{*}{10 questões } \\
\hline & 2.2 Implementação das Estratégias & \\
\hline \multirow{2}{*}{ 3. Clientes } & 3.1 Imagem e Conhecimento de Mercado & \multirow{2}{*}{12 questões } \\
\hline & 3.2 Relacionamento com os Clientes & \\
\hline \multirow{2}{*}{ 4. Sociedade } & 4.1 Responsabilidades Socioambiental & \multirow{2}{*}{11 questões } \\
\hline & 4.2 Desenvolvimentos Social & \\
\hline \multirow{2}{*}{$\begin{array}{l}\text { 5. Informações e } \\
\text { Conhecimentos }\end{array}$} & 5.1 Informações da Organização & \multirow{2}{*}{9 questões } \\
\hline & 5.2 Ativos Intangíveis e Conhecimento Organizacional & \\
\hline \multirow{3}{*}{ 6. Pessoas } & 6.1 Sistemas de Trabalho & \multirow{3}{*}{14 questões } \\
\hline & 6.2 Capacitação e Desenvolvimento & \\
\hline & 6.3 Qualidade de Vida & \\
\hline 7. Processos & 7.1 Processos Principais do Negócio e Processos de Apoio & 18 questões \\
\hline
\end{tabular}




\begin{tabular}{|l|l|l|}
\hline & 7.2 Processos relativos a Fornecedores & \multirow{2}{*}{} \\
\cline { 2 - 2 } & 7.3 Processos Econômicos Financeiros & \multirow{2}{*}{6 questões } \\
\hline \multirow{2}{*}{ 8. Resultados } & 8.1 Resultados Econômicos Financeiros & \\
\cline { 2 - 3 } & 8.2 Resultados Relativos a Clientes e ao Mercado & \\
\hline
\end{tabular}

Quadro 2 - Resumo do Modelo de Excelência da Gestão

Fonte: adaptado de FNQ (2009)

Cabe ressaltar que o MEG é composto por vários itens a serem analisados incorporados a cada critério, na qual se totalizam em 98 questões abertas a fim de determinar o estágio de maturidade da gestão. Isso torna o modelo complexo e de difícil entendimento para todas as partes interessadas e dos mais variados segmentos, além de requererem-se colaboradores adequados para aplicação. Partindo-se desse pressuposto, este estudo apresenta uma proposta simplificada de avaliação da gestão das entidades de classe.

\section{Método}

O trabalho iniciou-se pela fundamentação teórica, a partir de pesquisa da bibliografia existente acerca do tema e de assuntos afins. O material pesquisado foi organizado obedecendo à lógica da contextualização histórica da qualidade, visando à definição do modelo a ser adotado para a construção da Proposta Simplificada de Avaliação da Gestão das Entidades de Classe. Além disso, o estudo é classificado como pesquisa bibliográfica, que de acordo com Fachin (2003), diz respeito ao conjunto de conhecimentos humanos reunidos em obras, visando a proporcionar a produção, a coleção, o armazenamento, a reprodução, a utilização e a comunicação das informações coletadas. Utiliza-se desse tipo de pesquisa para discorrer sobre os oito Critérios do Compromisso com a Excelência da Fundação Nacional da Qualidade e o Modelo de Excelência da Gestão, de modo a fundamentar com a literatura pertinente.

Já o universo da presente pesquisa direciona-se às entidades de classe, estas se caracterizam por não terem fins lucrativos, com foco na representação e no desenvolvimento de suas associadas. Para Pernambuco (2012), essas entidades desenvolvem um importante papel de conscientização e fiscalização da sociedade, porque suas ações criam espaços culturais, promovem a cidadania, defendem o meio ambiente, valorizam o profissional, zelam pela ética e a defesa dos profissionais. Bem como, também estão empenhadas para atingir a qualidade, por meio da participação em premiações.

A partir disso, sugere-se uma Proposta Simplificada de Avaliação da Gestão das Entidades de Classe (PSAGEC) que possibilite mensurar e classificar os diferentes níveis de gestão, no intuito de auxiliar as organizações a melhorar o seu desempenho organizacional. Para a formulação do questionário, composto por 22 perguntas fechadas, utilizou-se os Critérios de Excelência do Prêmio Nacional da Qualidade, amparadas por um sistema de medição capaz de traduzir os aspectos de maior deficiência na gestão das entidades.

\section{Apresentação da Proposta Simplificada de Avaliação}

O modelo utilizado pela FNQ compreende inúmeros questionamentos em meio aos oito critérios anteriormente discutidos. Porém, o MEG torna-se pouco dinâmico por apresentar perguntas abertas e detalhistas, assim exige-se maior tempo para que a avaliação e análise dos dados aconteçam. Culminou-se a necessidade de se delinear e sugerir uma Proposta Simplificada de Avaliação da Gestão das Entidades de Classe (PSAGEC), aplicado aos dirigentes de tais entidades, conforme apresentada no Quadro 3. 
1 A Direção interage com as partes interessadas, disseminando e comprometendo com os valores e princípios organizacionais e buscando mobilização para o êxito das estratégias.

2 A Direção analisa o desempenho da organização, melhora as práticas de gestão e os respectivos padrões de trabalho.

3 A entidade possui um processo de formulação de estratégias que considera as necessidades das partes interessadas e utiliza indicadores para monitorar resultados.

4 As estratégias formuladas são desdobradas em planos de ação e são alocados recursos para assegurar a implantação dos planos de ação.

5 As necessidades e expectativas dos associados atuais e potenciais são identificadas, analisadas e transformadas em ações.

6 Eventuais reclamações ou sugestões dos associados são tratadas, é dado retorno e a satisfação é avaliada.

7 A entidade identifica e trata impactos sociais e ambientais adversos de seus produtos, processos e instalações.

8 A entidade fortalece a sociedade, envolvendo e incentivando a sua força de trabalho no apoio e execução de projetos sociais.

9 A entidade identifica as necessidades de informações e define os sistemas de informações necessárias para apoiar as operações diárias e a tomada de decisão, bem como utiliza informações comparativas pertinentes.

10 A entidade identifica seus principais ativos intangíveis, desenvolvendo-os e protegendo-os.

11 São definidos e implantados os cargos e as funções visando ao alto desempenho da entidade.

12 As necessidades de capacitação e desenvolvimento são identificadas e desenvolvidas considerando as necessidades estratégicas e das pessoas.

13 São identificados e tratados os fatores que afetam o bem-estar, a satisfação e a motivação das pessoas, considerando as necessidades de remuneração, reconhecimento e incentivos.

14 A entidade identifica e gerencia, por meio de indicadores, os processos principais e os processos de apoio analisando-os e melhorando-os.

15 O processo de gestão de fornecedores considera critérios de seleção, avaliação e informação de desempenho.

16 O processo econômico-financeiro estabelecido considera o fluxo de caixa, a orçamentação e as necessidades estratégicas, analisando e gerenciando sistematicamente.

Os indicadores estabelecidos acompanham os resultados disseminados para as partes interessadas pertinentes a:

17 Gestão econômico-financeira.

18 Clientes e mercado.

19 Sociedade.

20 Pessoas.

21 Produtos, processos principais e de apoio.

22 Fornecedores.

\section{Quadro 3 - Proposta de Avaliação da Gestão das Entidades de Classe} Fonte: elaborado pelos autores

Os questionamentos propostos detêm-se aos oito critérios abordados pelo MEG, porém não abrangem os variados itens. No modelo direcionado às entidades de classe as questões sobre cada critério variam entre 2 e 7 perguntas, e totalizam 22 questões. Ao contrário do MEG que possui uma variação entre 6 e 18 questões no contexto de 98 questões, conforme o Quadro 4. 


\begin{tabular}{|l|c|c|}
\hline \multicolumn{1}{|c|}{ Critérios de Avaliação } & $\begin{array}{c}N^{o} \text { de questões } \\
\text { Segundo FNQ (2009) }\end{array}$ & $\begin{array}{c}N^{o} \text { de questões } \\
\text { Proposta Simplificada }\end{array}$ \\
\hline Liderança & 18 & 2 \\
\hline Estratégias e Planos & 10 & 2 \\
\hline Clientes & 12 & 2 \\
\hline Sociedade & 11 & 2 \\
\hline Informações e Conhecimento & 9 & 3 \\
\hline Pessoas & 14 & 2 \\
\hline Processos Total & 18 & 7 \\
\hline Resultados Quadro & 6 & $\mathbf{2 2}$ \\
\hline
\end{tabular}

Quadro 4 - Diferença do ${ }^{\circ}$ de questões do MEG e da Proposta Simplificada

Fonte: elaborado pelos autores

Os questionamentos apresentados na proposta simplificada abrangem aspectos relevantes para a busca da excelência da gestão. Para que a análise do instrumento seja o mais próximo possível da realidade, apresentam-se cinco alternativas de respostas a cada questionamento. A partir das respostas deve ser considerar o critério de pontuação apresentado no Quadro 5:

\begin{tabular}{|l|c|}
\hline \multicolumn{1}{|c|}{ Respostas } & Pontuação \\
\hline Concordo totalmente & 4 \\
\hline Concordo parcialmente & 3 \\
\hline Indiferente & 2 \\
\hline Não concordo parcialmente & 1 \\
\hline Não concordo totalmente & 0 \\
\hline
\end{tabular}

Quadro 5 - Critério de pontuação

Fonte: elaborado pelos autores

Após a soma dos pontos dos 22 questionamentos, a entidade participante da pesquisa deve ser classificada de acordo com esse total de pontos, conforme Quadro 6.

\begin{tabular}{|c|c|}
\hline Escala do Total de Pontos & Situação da Gestão \\
\hline $80-88$ & Ótima \\
\hline $66-79$ & Muito boa \\
\hline $44-65$ & Boa \\
\hline $22-43$ & Regular \\
\hline $0-21$ & Insuficiente \\
\hline \multicolumn{2}{|c|}{ Quadro 6 - Classificação das empresas } \\
Fonte: elaborado pelos autores
\end{tabular}

Assim, a entidade pode-se comparar com outras, devido seus resultados serem fornecidos em categorias, tais como: grupo de benchmark, média das entidades e média da região na qual a entidade faz parte. Segundo a FNQ (2009, p.104), entende-se por benchmark ou referencial de excelência "organização, processo, produto ou resultado considerado o melhor da classe".

Contudo, ressalta-se que após a aplicação da pesquisa e a análise dos dados e interpretação, as entidades devem ser realimentadas com relatórios gerenciais, sigilosos, contendo a análise e sugestões de qualificação da gestão. Para isso sugere-se também que, para a aplicação do questionário, seja desenvolvida uma ferramenta de pesquisa web, onde será disponibilizado o questionário com acesso restrito a todos os Dirigentes das entidades pesquisadas. Justifica-se a utilização de ferramenta web em função do sigilo das informações, sendo possível o acesso ao 
questionário e às respostas apenas através do login e senha do dirigente da entidade participante, não possibilitando acesso às respostas do dirigente de outra entidade.

\section{Considerações Finais}

Após a realização deste estudo percebe-se que as Entidades de Classe estão buscando organizarse para unir forças e enfrentar o mundo globalizado, já que se tornou fundamental a busca pela excelência na gestão. O Modelo de Excelência da Gestão, elaborado pela Fundação Nacional da Qualidade, é o que parece melhor atender a tais necessidades. Com a percepção do cenário atual de cada um dos oito critérios do modelo (Liderança, Estratégias e Planos, Clientes, Sociedade, Informações e Conhecimento, Pessoas, Processos e Resultados), é possível ao gestor a visão sistêmica do processo, possibilitando atuar diretamente para reverter os possíveis problemas encontrados.

Como o modelo da FNQ parece ser um tanto complexo e genérico, pretendeu-se com esta pesquisa propor uma Proposta Simplificada de Avaliação da Gestão das Entidades de Classe (PSAGEC) que possibilite mensurar e classificar os diferentes níveis de gestão, no intuito de auxiliar as organizações a melhorar o seu desempenho organizacional. Após aplicação do instrumento e análise dos dados, será possível analisar, interpretar e concluir os pontos que merecem ser reavaliados de forma ágil e menos complexa por compreender-se em 22 questões fechadas.

Sugere-se que, no caso das entidades que aplicarem esta pesquisa, compartilhar a experiência com suas associadas, referindo à análise dos resultados e sugestões de melhoria, prestando relevante contribuição e atendendo suas missões. Após essa comunicação, várias ações poderão ser implantadas para reverter o quadro, como elaboração ou reavaliação do planejamento estratégico da organização; elaboração e/ou disseminação da missão, visão e valores junto a seus colaboradores buscando o comprometimento da equipe com as causas da organização; desenvolvimento de treinamentos para qualificação profissional; parcerias com outras entidades ou empresas; encontros para trocas de experiências entre associadas, entre tantas outras possíveis de serem implantadas.

É importante referir, também, que a Proposta de Avaliação da Gestão ora sugerido seja tratado como um instrumento capaz de fornecer subsídios para a tomada de decisão e de constituir-se em uma entrada para o plano de aperfeiçoamento da gestão organizacional. No entanto, o fato de ser um questionário não validado limitou-se o estudo. Por isso, acredita-se que o estudo não terminará por aqui. Sugere-se que o questionário proposto possa ser aplicado, como extensão a esta pesquisa em estudos futuros, possibilitando sua análise e conclusão dos resultados.

Salienta-se, para tanto, que, em função do referido trabalho ser uma proposta, o mesmo não apresenta resultados aplicados. Esse está direcionado à construção de um modelo simplificado de avaliação da gestão de entidades de classe, a partir dos critérios utilizados pela Fundação Nacional da Qualidade, que poderá ser aplicado pelas organizações.

\section{Referências}

ALMEIDA, M. I. R.; ASAI, L. N. A influência da Globalização nas Pequenas Empresas. In: XIV CONGRESSO LATINO AMERICANO DE ESTRATÉGIA, 2001, Buenos Aires. SLADE, 2001.

ARREBOLA, M. C. Responsabilidade Social Corporativa: Competitividade e Desenvolvimento Social. A Prática do Setor Supermercadista. Disponível em: $<$ http://www.ead.fea.usp.br/semead/7semead/paginas/artigos\%20recebidos/Socioambiental/SA2

7_Resp_Social_Corporativa_Competivividade.PDF>. Acesso em: 23/01/2014. 
BORGES, A.; BAYLÃO, A. Liderança em Tempo de Mudanças. Disponível em: $<$ http://www.administradores.com.br/informe-se/producao-academica/lideranca-em-tempo-demudancas/331/>. Acesso em: 19/01/2014.

CARVAlho, M. M. de; PALAdINI, E. P. Gestão da Qualidade. 2. Ed. Rio de Janeiro: Elsevier, 2012.

FACHIN, O. Fundamentos de Metodologia. São Paulo: Saraiva, 2003.

FERNANDES, B. H. R.; BERTON, L. H. Administração estratégica: da competência empreendedora à avaliação de desempenho. São Paulo: Saraiva, 2006.

FUNDAÇÃO NACIONAL DA QUALIDADE (FNQ). Conceitos Fundamentais da Excelência em Gestão. São Paulo, 2006.

. Critérios Compromisso com a Excelência e Rumo à Excelência. São Paulo, 2009.

.Correlação entre fundamentos e critérios. Disponível em: $<\mathrm{http}$ //fnq.org.br/avalie-se/metodologia-meg/modelo-de-excelencia-da-gestao/correlacao-entrefundamentos-e-criterios $>$. Acesso em: 20/01/2014.

GARVIN, D. A. Gerenciando a Qualidade: a visão estratégica e competitiva. Tradução de João Ferreira Bezerra de Souza. Rio de Janeiro: Qualitymark, 2002.

GIOVANONI, A. Perspectivas da gestão da qualidade nas empresas. Disponível em: $<\mathrm{http}: / /$ www.comunicare2.com.br/noticia.asp? $\operatorname{codEdicao}=327 \& \operatorname{codJ}$ ornal $=\quad 27 \&$ numNoticia $=4>$. Acesso em: 11/01/2014.

HUNTER, J. Como se Tornar um Líder Servidor: os princípios de liderança de o monge e o executivo. Rio de Janeiro: Sextante, 2006.

LIMA, A. Tom Peters e a busca da excelência. Disponível em: $<$ http://www.administradores.com.br/artigos/carreira/tom-peters-e-a-busca-daexcelencia/22690/>. Acesso em: 17/01/2014.

MACEDO, A. Na administração por processos, o cliente é o foco. Disponível em: $<$ http://www.canalrh.com.br/revista/revista_artigo.asp?o=\%7B43AB0F25-5BB9-472D-A6C96EA12C8DF48F\%7D>. Acesso em: 23/01/2014.

MALAQUIAS, A. Fidelização de Clientes. Disponível em: $<\mathrm{http}: / /$ www.techoje.com.br/site/techoje/categoria/detalhe_artigo/871>. Acesso em: 20/01/2014.

MARQUES, F. Guia prático da excelência em serviços: como conquistar clientes, aumentar o lucro e viver melhor. São Paulo: Nobel, 2006.

MARTINS, R.A.; COSTA NETO, P. L. O. Indicadores de Desempenho para a Gestão pela Qualidade Total: uma proposta de sistematização. Gestão \& Produção, São Carlos-SP, v.5, n. 3, p. 298-311, dez., 1998. 
OLIVEIRA, D. Administração de Processos: Conceitos, metodologia e práticas. São Paulo: Atlas, 2006.

PADULA, R. Reflexões Gerais sobre Políticas Públicas e Desenvolvimento Local na Era da Globalização. Disponível em: <http://www.eumed.net/rev/oidles/01/Padula.htm>. Acesso em: 23/01/2014.

PERNAMBUCO, M. A. O verdadeiro papel das entidades de classe. Instituto Brasileiro de

Desenvolvimento
http://www.forumdaconstrucao.com.br/conteudo.php?a=0\&Cod=234>. Acesso em: 13/06/2012.

SANTIAGO JR, J. Gestão do Conhecimento: a chave para o sucesso empresarial. São Paulo: Novatec, 2004.

TRAVASSOS, A. Recursos Humanos: como gerenciá-los em projetos? Curitiba, Revista Mundo Project Management, ano 4, n. 21, 2008. 